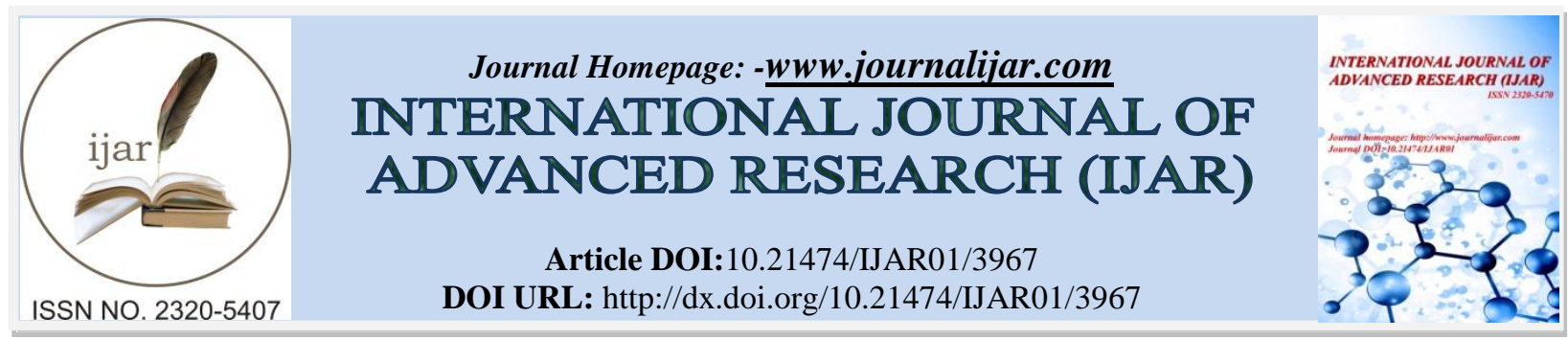

RESEARCH ARTICLE

\title{
PREVALENCE OF DEPRESSION, ANXIETY AND STRESSAMONG THE UNDERGRADUATE MEDICAL STUDENTS OF PRINCE SATTAM BIN ABDULAZIZ UNIVERSITY, ALKHARJ, SAUDI ARABIA.
}

Sandeep Agrawal, Mohammed Yousef Aleid, Rakan Turki Alotaibi, Mustafa Mohammed Alwusaybie,
Othman Mohmmed Almousa, Hosam Monahe Aldalbahi and Saad Mohammed Al-Haqbani

\section{Manuscript Info}

Manuscript History

Received: 17 February 2017

Final Accepted: 07 March 2017

Published: April 2017

Key words:-

Stress, Anxiety, Depression, Mental Health, DASS- 21.

\section{Abstract}

Background: Contemporary literature suggests that medical education might adversely affect students' mental health. Prince Sattam Bin Abdulaziz University of Alkharj, Saudi Arabia is a developing institution hence there was a concern regarding the mental well-being of the medical students.

Aim:Few similar studies have been carried out in Saudi Arabia but none in Alkharj region. So there was need to assess the prevalence of depression, anxiety and stressamong the undergraduate medical students studying at Prince Sattam Bin Abdulaziz University of Alkharj.

Methodology:All male undergraduate medical students across the 5 years of study were includedin this cross-sectional study by filling out anonymously the standard Depression, Anxiety, and Stress Scale-21 (DASS-21) questionnaire and another questionnaire containing socio demographic details.

Results: A total of $92.5 \%$ of medical students eventually participated in the study. All of them were Saudi males. The prevalence of Depression, Anxiety and Stress among undergraduate medical students was found to be $39.5 \%, 56.2 \%$ and $37.2 \%$ respectively.Smoking was associated with higher levels of stress. The students perceived the academic pressureto be the primary cause of their adverse mental health.

Conclusion:The prevalence of Depression, Anxiety and Stress among undergraduate medical students was found to be $39.5 \%, 56.2 \%$ and $37.2 \%$ respectively. Academic stress, academic hours \& emotional state were the major reasons causing Depression, Anxiety and Stress while spending time with friends, watching television and playing sports were the major de-stressing activities among undergraduate medical students.

Copy Right, IJAR, 2017,. All rights reserved.

\section{Introduction:-}

Medical education is very challenging and stressful, and needs really hard work to become a knowledgeable physician. The greater the mental health of a person, the better is his well-being and the capacity to overcome troubles and lifelong problems. (1) The stressful academic environment in the field of medicine can exert a negative effect on the psychological and physical well-being of medical students. (2). 
The various causes of stressin medical education have been reported to be due to academic demands, examinations, inability to cope, helplessness, increased psychological pressure, and too much work load. (3)High levels of stress may have a negative effect on cognitive functioning and studying of the academic curriculum of a medical student. In many medical schools, the environment itself can cause significant pressure among medical students due to its authoritarian and rigid system which encourages competition rather than cooperation between learners. $(4,5)$

The estimated prevalence of emotional disturbance found in different studies on medical students was higher than that in the general population. In a British study, the prevalence of stress among medical students was found to be $31.2 \%$ (6). In comparison, a Swedish study had prevalence of depression as $12.9 \%$, with $2.7 \%$ of students who made suicidal attempts. (7) In another study done in Saudi Arabia, the prevalence of depression, anxiety, and stress was found to be $43 \%, 63 \%$, and $41 \%$, respectively which reduced to $30 \%, 47 \%$, and $30 \%$, respectively after examinations.(8).

Stress in medical school can lead to mental health problems later in life but students seldom seek help for their problems. (9)Medical students are a unique group as they are in many ways responsible for the health of the broader population in future and thus one might believe they should be more carefully scrutinized. It is therefore important for medical educators to know the prevalence and predictors of depression, anxiety and stress among students, which can adversely affect their physical, mental and social well-being.

\section{Aim:-}

Few similar studies have been carried out in Saudi Arabia but none in Alkharj region. So there was need to assess the prevalence of Depression, Anxiety and Stress among the undergraduate medical students studying at Prince Sattam Bin Abdulaziz University of Alkharj.

\section{Objectives:-}

1. To findthe prevalence ofDepression, Anxiety and Stress among the undergraduate medical students of Prince Sattam Bin Abdulaziz University, Alkharj, Saudi Arabia.

2. To find out the various factors associated with Depression, Anxiety and Stress.

\section{Materials and Methods:-}

Study period: The study was carried out between September 2015 and December 2015.

Study Area: University Campus, College of Medicine, Prince Sattam Bin Abdulaziz University.

Study Subjects:Male undergraduate medical students.

Study design: Cross-sectional study.

Sample size: All male undergraduate medical students studying at the college of medicine in Prince Sattam Bin Abdulaziz University were included in the study.(Therewere no female medical students in the university). Using 'Raosoft software' (11), with a total study population of 200 and a 5\% margin of error with $95 \%$ confidence interval, the required sample size came out to be 132 .

\section{Study Population:-}

Inclusion Criteria: All undergraduate medical students who gave verbal informed consent were included in the study.

\section{Exclusion Criteria:-}

Following were excluded:

1. Students who couldn't be contacted after two attempts.

2. Students who did not give their consent.

\section{Study Tools:-}

1) A standard self-administered questionnaire DASS-21 was used in this study to elicit the presence of depression, anxiety and stress in the study population.(10)

The Depression Anxiety Stress Scales (DASS)-21 is a 21 item self-report instrument designed to measure the three related negative emotional states of depression, anxiety and stress. It has 7 items each on depression, anxiety and stress. Each item has to be rated by a four-point rating scale. The rating scale is as follows:

0 Did not apply to me at all - NEVER 
1. Applied to me to some degree, or some of the time - SOMETIMES

2. Applied to me to a considerable degree, or a good part of time - OFTEN

3. Applied to me very much, or most of the time - ALMOST ALWAYS

The final scoring is done by adding 7items (and multiplying by 2) each of depression, anxiety and stress and they subsequently are categorized as normal, mild, moderate, severe and extremely severe according to scoring shown below.

Dass Scale Scoring:-

\begin{tabular}{|l|l|l|l|}
\hline & DEPRESSION & ANXIETY & STRESS \\
\hline NORMAL & $0-9$ & $0-7$ & $0-14$ \\
\hline MILD & $10-13$ & $8-9$ & $15-18$ \\
\hline MODERATE & $14-20$ & $10-14$ & $19-25$ \\
\hline SEVERE & $21-27$ & $15-19$ & $26-33$ \\
\hline EXTREMELY SEVERE & $28+$ & $20+$ & $34+$ \\
\hline
\end{tabular}

The DASS-21 is in public domain and no permission is needed to use it. It has high internal consistency.

DASS-21 was translated to Arabic language and then translated back to English for validation and was further validated by three consultant physicians. A semi-open ended and self-prepared questionnaire was used in study for (A) socio demographic details, (B) identifying the factors associated with depression, anxiety and stress.

The information collected was kept confidential and anonymity is maintained.

\section{Sampling Procedure and Data Collection:-}

A written permission was obtained from the Dean of the college of medicine prior to conducting the study. The total number of enrolled medical students was found to be 200 . The pilot testing was done in 10 undergraduate medical students 2 students from each academic level but this was not included in the final collected data. The students were personally contacted by the researcher. The standard questionnaire DASS-21 and another self-prepared questionnaire was handed over to the respondents for filling up andwere collected in the same visit. The responses were sought in a self-reported, anonymous fashion. Eventually data was collected from 185 medical students out of 200 . Five students either did not give their consent or were unavailable during data collection.

\section{Ethical Considerations:-}

A written permission was obtained from the dean of college of medicine prior to conducting the study. Verbal informed consent was taken from each respondent before providing the questionnaire for filling up. IRB permission was also taken with IRB No. PSAU-MED-2015-12/14/PI

\section{Statistical Analysis:-}

The information collected on the tools was transferred to a Microsoft Excel Sheet to make a master chart of the whole data. Subsequently analysis of the data was done on the SPSS software version 20. Appropriate statistical testincluding the chi-square testwas applied(categorical data)to find association of various factors with depression, anxiety and stress. p -value less than 0.05 was considered significant.

\section{Results:-}

Out of total 200 medical students and the required sample size of 132, data was finally collected from 185 students. The mean age of the study population was found to be 21.5 years with a standard deviation of 1.5 . The majority of the students were single and more than half of them declare themselves as nonsmokers.The socio-demographic details of the study population are shown in Table 1. 
Table 1:-Socio Demographic Details of The Study Population.

\begin{tabular}{|c|c|c|}
\hline Parameters & Frequency & Percent \\
\hline \multicolumn{3}{|l|}{ Enrollment } \\
\hline 2st Year & 50 & 27.0 \\
\hline 3nd Year & 45 & 24.3 \\
\hline 4rd Year & 42 & 22.7 \\
\hline 5th Year & 26 & 14.1 \\
\hline 6th Year & 22 & 11.9 \\
\hline Total & 185 & 100.0 \\
\hline \multicolumn{3}{|c|}{ Marital Status } \\
\hline Married & 8 & 4.3 \\
\hline Single & 177 & 95.7 \\
\hline \multicolumn{3}{|c|}{ Living With Family } \\
\hline Yes & 139 & 75.1 \\
\hline No & 46 & 24.9 \\
\hline \multicolumn{3}{|c|}{ Chronic Disease } \\
\hline Present & 18 & 9.7 \\
\hline Absent & 167 & 90.3 \\
\hline \multicolumn{3}{|l|}{ Smoking } \\
\hline Yes & 33 & 17.8 \\
\hline No & 152 & 82.2 \\
\hline \multicolumn{3}{|c|}{ Willingness to Continue in Medical School } \\
\hline Yes & 140 & 75.7 \\
\hline No & 44 & 23.8 \\
\hline \multicolumn{3}{|c|}{ Family History of Psychiatric Illness } \\
\hline Yes & 35 & 18.9 \\
\hline No & 150 & 81.1 \\
\hline \multicolumn{3}{|c|}{ Doing Exercise } \\
\hline Yes & 97 & 52.4 \\
\hline No & 88 & 47.6 \\
\hline
\end{tabular}

The overall prevalence of Depression, Anxiety and Stress among the medical students was found to be 39.5\%, $56.2 \%$ and $37.2 \%$ respectively. The results have been shown it Table $\mathbf{2 , 3}$ and $\mathbf{4}$.

Table 2:-Prevalance Of Depression among Study Population.

\begin{tabular}{|l|l|l|}
\hline DEPRESSION & Frequency & Percent \\
\hline Normal & 112 & 60.5 \\
\hline Mild & 31 & 16.8 \\
\hline Moderate & 23 & 12.4 \\
\hline Sever & 14 & 7.6 \\
\hline Extremely Sever & 5 & 2.7 \\
\hline Total & 185 & 100.0 \\
\hline
\end{tabular}

Table 3:-Prevalence Of Anxiety among Study Population.

\begin{tabular}{|l|l|l|}
\hline ANXIETY & Frequency & Percent \\
\hline Normal & 81 & 43.8 \\
\hline Mild & 25 & 13.5 \\
\hline Moderate & 44 & 23.8 \\
\hline Sever & 16 & 8.6 \\
\hline Extremely Sever & 19 & 10.3 \\
\hline Total & 185 & 100.0 \\
\hline
\end{tabular}


Table 4:- Prevalence Of Stress among Study Population.

\begin{tabular}{|l|l|l|}
\hline STRESS & Frequency & Percent \\
\hline Normal & 116 & 62.8 \\
\hline Mild & 23 & 12.4 \\
\hline Moderate & 30 & 16.2 \\
\hline Sever & 14 & 7.6 \\
\hline Extremely Sever & 2 & 1.1 \\
\hline Total & 185 & 100.0 \\
\hline
\end{tabular}

Figure 1:-Association Of Depression, Anxiety And Stress With Academic Year

\section{ASSOCIATION OF DEPRESSION, ANXIETY AND STRESS WITH ACADEMIC YEAR}

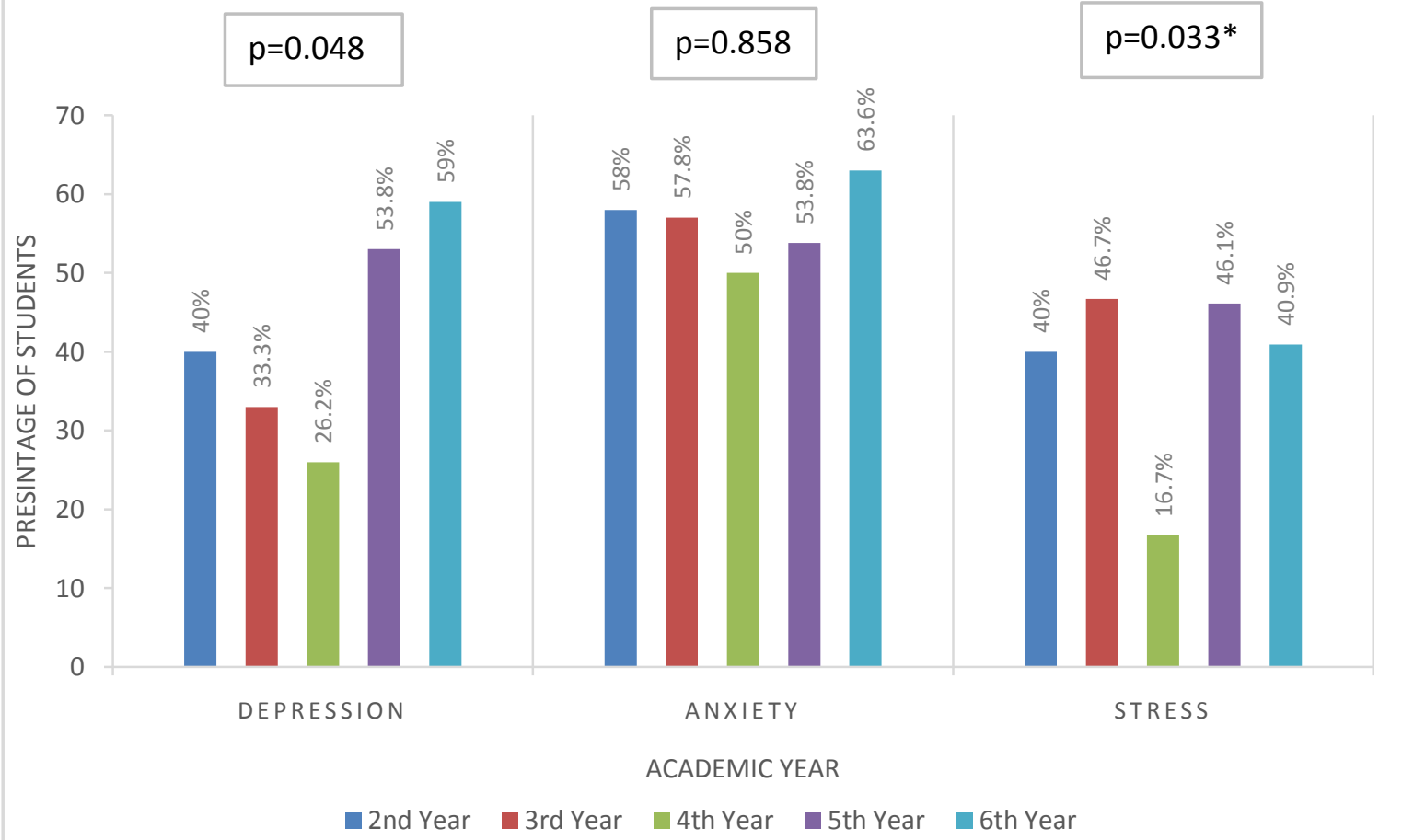

It was found in our study that there was an association between the academic year and depression levels. It can be seen from Figure 1that the depression $(\mathrm{p}=0.048)$ was more prevalent in the early and later academic years and this difference in academic years was found to be significant.It was also seen that stress was significantly low in the 4th year in comparison to other academic years $(\mathrm{p}=0.033)$.

Table 5:-Association Of Depression, Anxiety And Stress With Living With Family.

\begin{tabular}{|l|l|l|l|l|}
\hline \multirow{2}{*}{ Parameters } & \multicolumn{2}{|c|}{ Living With Family } & \multirow{2}{*}{ Significance Level } \\
\cline { 3 - 4 } Depression & Yes & No & \\
\cline { 2 - 4 } & Normal & 55 & 18 & \multirow{2}{*}{$\mathrm{p}=0.958$} \\
\hline \multirow{2}{*}{ Anxiety } & Present & 83 & 28 & \\
\cline { 2 - 4 } & Normal & 56 & 21 & $\mathrm{p}=0.096$ \\
\hline \multirow{2}{*}{ Stress } & Present & 46 & 25 & \\
\cline { 2 - 4 } & Normal & 93 & 23 & $\mathrm{p}=0.040^{*}$ \\
& & & & \\
\hline
\end{tabular}

As shown in Table 5,it was found that the students living with their families had lower levels of stress in comparison to students living without their families $(\mathrm{p}=0.040)$. 
Table 6:-Association of Depression, Anxiety And Stress With Smoking.

\begin{tabular}{|l|l|l|l|l|}
\hline \multirow{2}{*}{\multicolumn{2}{|c|}{ Parameters }} & \multicolumn{2}{l|}{ Smoking } & \multirow{2}{*}{ Significance Level } \\
\cline { 2 - 4 } Depression & Yes & No & \\
\hline \multirow{2}{*}{ Anxiety } & Present & 17 & 56 & \multirow{2}{*}{$\mathrm{p}=0.118$} \\
\cline { 2 - 4 } & Absent & 16 & 96 & \\
\hline \multirow{2}{*}{ Stress } & Present & 22 & 82 & \multirow{2}{*}{$\mathrm{p}=0.182$} \\
\cline { 2 - 4 } & Absent & 11 & 70 & \\
\cline { 2 - 4 } & Present & 18 & 51 & $\mathrm{p}=0.024 *$ \\
\cline { 2 - 4 } & Absent & 15 & 101 & \\
\hline
\end{tabular}

We found in our study that smokers had higher level of stress in comparison to non-smokers $(\mathrm{p}=0.024)$. $($ Table-6)

Figure 2:-Causes Of Stressamong Study Population

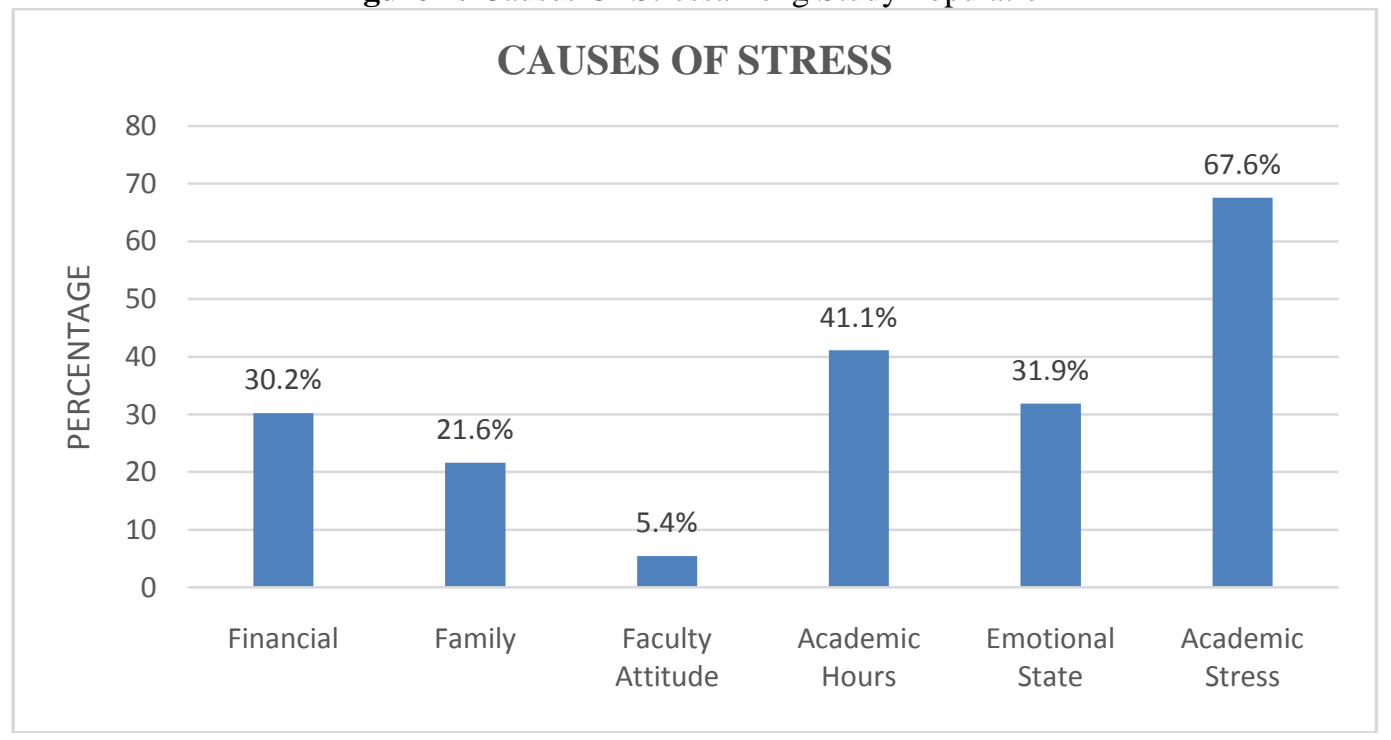

On being asked about the causes of stress, students responded academic stress, academic hours and emotional state as major reasons of stress. Faculty attitude, familial issues and financial worries were some other reasons as shown in Figure 2. 
Figure 3:-De-Stressing Activities Among Undergraduate Medical Students

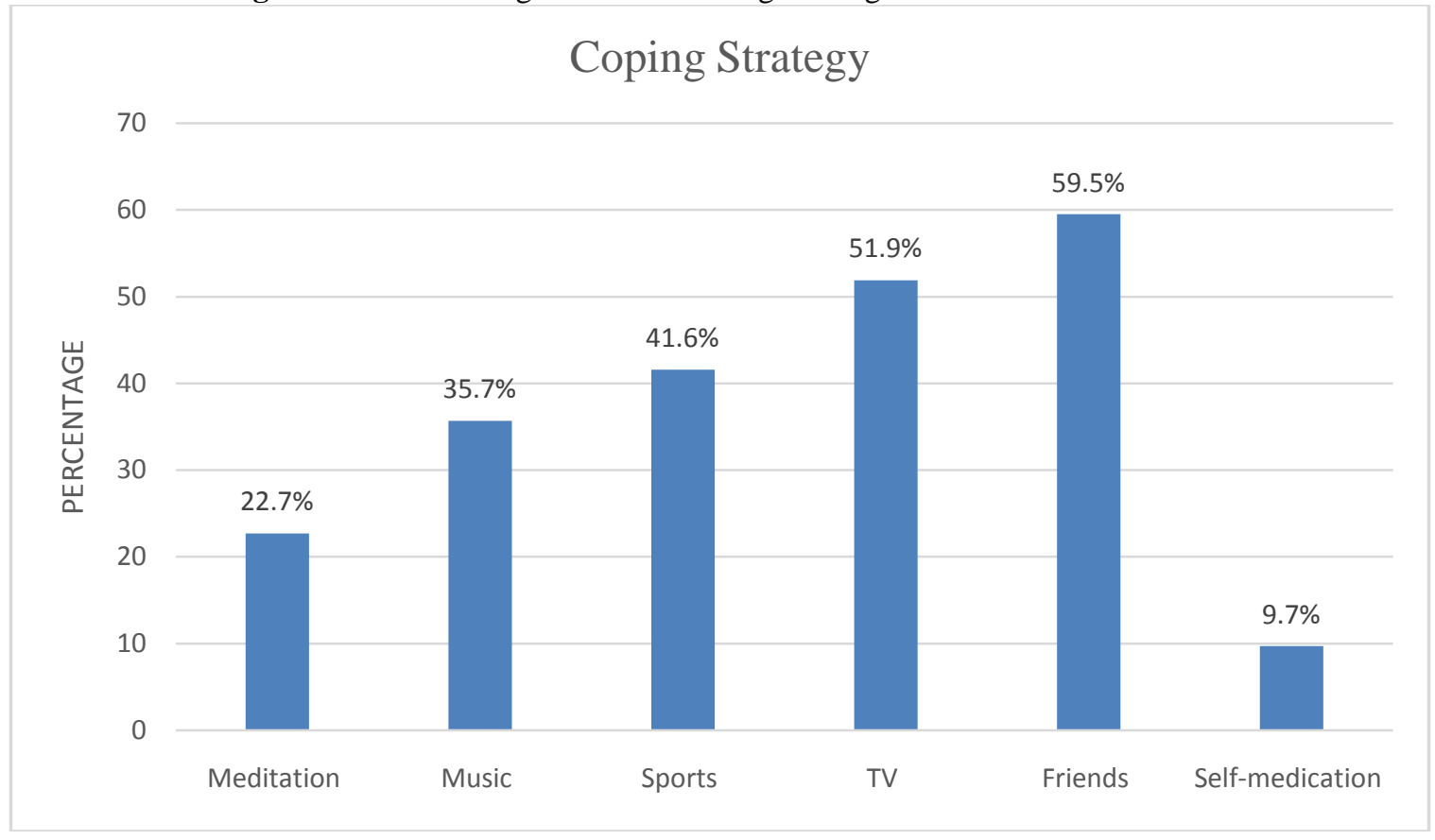

On being enquired, the students told that spending time with friends, watching television and playing sports were the major de-stressing activities adopted by them. Listening to music, doing meditation and self-medication were some other strategies adopted by them as shown inFigure 3 .

\section{Conclusions:-}

It was concluded from this cross-sectional study that

1. The prevalence of Depression, Anxiety and Stress among undergraduate medical students was found to be $39.5 \%, 56.2 \%$ and $37.2 \%$ respectively.

2. Academic stress, academic hours \& emotional statewere the major reasons causing stress among undergraduate medical students.

3. Spending time with friends, watching television and playing sportswere the major de-stressing activities among undergraduate medical students.

\section{Recommendations:-}

1. Academic hours may be regulated to avoid mental health problems.

2. Promotion of de-stressing activities like meditation, sports and interaction with family and friends may be done among the medical students.

3. Recreational facilities may be made available in the hospital and campus to reduce the level of stress among medical students.

\section{Limitations:-}

1. It was a questionnaire based study so the responses made by the students may not be a true information.

2. Self-prepared questionnaire was not a standard questionnaire.

3. Since it was a cross sectional study, the data collected was of a much smaller duration of time and did not compare pre-exam time and post exam time.

\section{Acknowledgements:-}

We firstly would like to thank our undergraduate medical students for volunteering in our research project. We are grateful to Prof. Sanaa Kamal, Consultant of Gastroenterology for assisting us in statistical analysis and validation of the questionnaires. We highly appreciate the guidance and cooperation of Dr. JamaanAlzahrani, Dr. Sameer H. Al-Ghamdi, Dr. Khalid KhalafAldossari, Dr. Saad Al-Shaharni and Dr. Deepak Pathaniathroughout our research and 
for translating and validating our questionnaires. We also would like to thank our Dean, Dr. Abdurrahman I. Al Theyab and vice dean, Dr. Salman bin Dayel for giving the permission for conducting our study in the university campus.

\section{References:-}

1. Ahmed I, Banu H, Al-Fageer R, Al-Suwaidi R.Cognitive emotions: depression and anxiety in medical students and staff. J Crit Care. 2009 Sep;24(3):e1-7.

2. YusoffM ,Abdul Rahim A, Yaacob M.Prevalence and Sources of Stress among UniversitiSains Malaysia Medical Students.Malays J Med Sci. 2010 Jan-Mar; 17(1): 30-37.

3. Shaikh B, Kahloon A, Kazmi M, Khalid H, Nawaz K, Khan N, Khan S. Students, stress and coping strategies: a case of Pakistani medical school.Educ Health (Abingdon). 2004 Nov;17(3):346-53.

4. AbdulghaniH, AlKanhalA , Ebrahim S, PonnamperumaG, andAlfaris E. Stress and Its Effects on Medical Students: A Cross-sectional Study at a College of Medicine in Saudi Arabia. J Health PopulNutr. 2011 Oct; 29(5): 516-522.

5. Stewart SM, Lam TH, Betson CL, Wong CM, Wong AM. A prospective analysis of stress and academic performance in the first two years of medical school. Med Educ. 1999 Apr;33(4):243-50.

6. Firth J. Levels and sources in medical students. BMJ 1986;292:1177-80.

7. Dahlin M, Joneborg N, Runeson B. Stress and depression among medical students: a cross-sectional study. Med Educ 2005;39:594-604.

8. Kulsoom B, Afsar NA. Stress, anxiety and depression among medical students in a multiethnic setting.Neuropsychiatr Dis Treat. 2015 Jul 16;11:1713-22.

9. Tyseen R, Vaglum P, Gronvold NT, Ekeberg O. Factors in medical school that predict postgraduate mental health problems in need of treatment. A nationwide and longitudinal study. Med Educ 2001;35:110-20.

10. Henry JD, Crawford JR. The short-form version of the Depression Anxiety Stress Scales (DASS-21): construct validity and normative data in a large non-clinical sample. Br J Clin Psychol. 2005;44: 227-239.

11. Raosoft [homepage][last accessed on 16/12/2015] Available from:URL: http://www.raosoft.com/samplesize.html 